\title{
An empirical analysis of the impact of technological innovation on China's total employment
}

\author{
Peihua $\mathrm{Li}^{1}$ \\ ${ }^{1}$ Beijing Jiaotong University, Beijing, ChinaC
}

\begin{abstract}
Technological innovation represented by artificial intelligence and 5G networks has developed rapidly, since the reform and opening up, especially in recent years. Technological innovation promotes the upgrading of industrial structure, promotes the increase of employment in emerging industries, at the same time, eliminate the workers in backward industries, which will have an impact on overall employment. Therefore, this paper studies the impact of technological innovation on the total employment of China from an empirical perspective. Total Factor Productivity (TFP) and TFP growth rate calculated by the Solow residual method are used as indicators of the level of technological innovation, and the long-term cointegration regression model and short-term impulse response function are established with the number of employees and employment growth rate as the dependent variables, respectively. The study found that, the impact of technological innovation on employment levels has a stable promotion effect in the long run; in the short run, there is a destructive effect at first, but as time goes by, this destructive mechanism gradually occupies the peak, and the creative mechanism begins to take effect. The leading role, technological innovation has a steady promotion effect on employment.
\end{abstract}

\section{Introduction}

The level of scientific and technological innovation has increased unprecedentedly, with the in-depth development of reform and opening up. Workers in backward industries are forced to lose their jobs, meanwhile some new industries are absorbing employment, exposing increasingly prominent employment problems. However, social development is inseparable from technological innovation, and social harmony is inseparable from full employment. For society to develop harmoniously, it is necessary to understand the effect of technological innovation on employment. Therefore, in the context of the current powerful in science and technology, clarifying the relationship between technological innovation and employment and exploring the mechanism of organic integration and benign interaction between the two, not only has great theoretical significance, but also has very urgent practical significance.

In view of this problem, this paper selects scientific and technological innovation as the explanatory variable, explores its impact mechanism on China's employment, and selects the relevant data from 1978-2018 in China to establish empirical analysis by establishing a cointegration regression model and impulse response function.

\section{Previous research}

As for the impact of scientific and technological innovation on employment in China, Chinese scholars have been aware of this point for a long time, and continue to study and expand it.

Xianping Bi and Jianyi Zhao used regression, co integration analysis and error correction model to study the problem and found that, the rapid development of scientific and technological innovation has no clear impact on the change of employment in the long run, but significantly affects on the change of employment structure in China[1].

Guangdong Wang, Rensun Ye and Lei Wang used DEA method to measure TFP[2]. The empirical analysis shows that the total employment and employment structure are significantly affected by scientific and technological innovation. Scientific and technological innovation will bring more employment opportunities in the developed areas. While in the underdeveloped areas, scientific and technological innovation will produce employment destruction effect.

Zhen Chen found that scientific and technological innovation will not only bring part of employment, but also cause certain unemployment. Whether scientific and technological innovation can promote employment or cause unemployment depends on the effect of both[3].

Maosheng Ran and Yali Zou used the implicit variable method to estimate the scientific and technological innovation rate, and then analyzed the dynamic impact of 
scientific and technological innovation on the total employment growth through the impulse response[4]. It is found that the impact of technological innovation on employment change is significantly negative in the short term (1-3 years), but significantly positive in the long term (4-8 years).

Based on DEA Malmquist productivity index, Youping Cui, Yuguo Jin and Xiao Wang found that TFP and technological innovation have significantly negative effects on employment, but technological efficiency has no significant effect on employment[5].

\section{Theoretical research and Abbreviations and Acronyms}

The theory of the effect of scientific and technological innovation on employment has been put forward for a long time. Smith (1776), the first researcher, pointed out that the premise of continuous expansion is the increase of "productive" labor, which will bring about changes in employment structure. Since then, each school has made further theoretical research on the impact of technological innovation on employment.

\subsection{The mystery of Ricardo - classical economic theorys}

Ricardo pointed out that labor-saving machines make production easier, reduce prices, stimulate consumption, and lead to expansion of production, which will lead to more employment in his book Principles of political economy and Taxation. That is, technological progress will create new jobs and promote employment. However, with the wide use of large machines, the contradiction that machines replace labor is increasingly prominent. Ricardo then realized that scientific and technological innovation gave birth to many new machines, but these machines replaced the labor force, making the demand for labor force lower and lower, thus causing more and more unemployment. That is, scientific and technological innovation had a negative impact on employment[6].

\subsection{Marxist Theory}

Marx's theory points out that the growth rate of labor substitution caused by scientific and technological innovation is much higher than the growth of labor demand caused by capital accumulation in the short term, which will lead to the continuous decline of the absolute amount of labor combined with the same material means of production and the existence of relative surplus population. That is to say, scientific and technological innovation will lead to the accumulation of capital instead of employing labor force, which will lead to unemployment. However, technological innovation will bring about the continuous expansion of social and economic scale and the corresponding improvement of labor productivity in the long run. The improvement of labor productivity will bring more capital accumulation to enterprises and promote enterprises to increase investment to expand production scale, then coordinate the common development of related upstream and downstream industries. This kind of interaction and collaborative development will bring more detailed specialization and promote the development of nonproduction industries. A large number of workers can choose either the former productive industries or the later nonproductive industries, so that promote social employment.

\subsection{Schumpeter's theory of creative destruction - the theory of Innovative Economics}

Joseph Schumpeter, a famous economist, believed in his research in 1939 that the process of technological change was born irregular and unbalanced, and these revolutionary new technologies could set off a "creative hurricane of destruction"[7]. It will bring periodic fluctuations to the social economy, new technology will gradually replace the old technology, new economic structure, emerging industries and employment opportunities will follow, bringing about economic adjustment and fluctuation, replacement of the old and new industries, then causing the transformation of workers between jobs, resulting structural unemployment in shortterm. Schumpeter's theory of innovation and economic cycle has opened up a new way on the research of scientific and technological innovation. He believes that the unemployment caused by scientific and technological innovation is inevitable and the inherent drawback of the whole society.

\subsection{Romer's endogenous economic growth model - new economic growth theory}

In the 1980s, Paul Romer, as a representative of the new economic growth theory, internalized the impact of technological innovation on economic growth, namely endogenous economic growth theory[8]. He analyzed the impact of scientific and technological innovation on employment by establishing production function, and regarded scientific and technological innovation as another important production factor independent of labor and capital. He discusses the impact of technology on employment with economic growth as the intermediate variable through the proportional relationship between different factors. Scientific and technological innovation leads to the growth of economic aggregate, which in turn creates more jobs. In addition, scientific and technological innovation will improve the knowledge literacy and human capital of workers, and the improvement of personal skills will increase the employment opportunities of workers. From Romer's theory of new economic growth, we can find that as long as the economy continues to grow at a high speed, the positive effect of employment will be enough to offset its destructive effect and achieve employment growth.

\section{Influence mechanism analysis}

At present, most scholars generally believe that technological innovation has two-sided effect on employment, both creation effect and destruction effect on 
employment. What kind of mechanism does technological innovation affect employment? I will make a qualitative analysis on the path of technological innovation's impact on employment.

The impact of technological innovation on employment is based on the following assumptions.

Consumption tendency is positive.

- Excluding the wage stickiness caused by the efficiency wage, insiders and outsiders, the wage level can be changed freely and the market regulation mechanism is effective.

- According to the different impacts of technological innovation on different industries, this paper divides the industries into three categories, one is the emerging industry generated by technological innovation, which is recorded as $\mathrm{N}$ industry; the other is the old industry that will be replaced by the social process and will soon disappear due to the impact of technological innovation, which is recorded as $\mathrm{O}$ industry, the last one is the state that most industries are facing, that scientific and technological innovation has no direct impact on it. It is mainly affected by the microwave effect brought by scientific and technological innovation, which is recorded as G industry.

- On the issue of capital to labor substitution, different industries have different substitution ratios. This paper assumes that the replacement rate of capital to labor is very low in $\mathrm{N}$ industry, which can be regarded as capital can't replace labor. For the $\mathrm{O}$ industry, the replacement rate of capital to labor is particularly high, which can almost be completely replaced, For the G industry, capital can replace labor to some extent, but labor is the main force.

\subsection{Price effect}

Scientific and technological innovation leads to the increase of social labor productivity and the decrease of product price. In the case of a certain amount of money, consumers can buy more goods, that is, the actual purchasing power of money has been improved, thus increasing the demand for consumer goods. We have assumed that there is a positive consumption trend before. So enterprises will inevitably expand production scale in order to meet the increase of market demand. For general $\mathrm{G}$ industry, capital can't completely replace the labor force, which will inevitably lead to the increase of labor demand, bring more jobs, increase employment opportunities, and have a positive impact on employment.

\subsection{Cost effectiveness}

On the one hand, scientific and technological innovation leads to the improvement of social labor productivity, the increase of unit labor output, resulting in the decrease of unit output labor cost. Enterprises employ more labor to reduce product cost, that is to say, use labor instead of capital. This labor-intensive production mode provides more employment opportunities for the society and creates impact on employment. On the other hand, the increase of labor productivity makes the production of products with the same output no longer need as much labor force, which leads to the decrease of labor demand and employment opportunities. This kind of scientific and technological innovation leads to the increase of production efficiency and the decrease of production cost, which also directly produces the crowding out effect on employment.

\section{Model}

\subsection{Technological innovation - Growth rate of TFP}

Using Solow residual method to calculate TFP. In Solow model, TFP is the balance of output economic growth rate after deducting the contribution of labor and capital. Production function adopts Cobb Douglas production function,

$$
Y_{t}=A K_{t}^{\alpha} L_{t}^{\beta}
$$

$Y_{t}$ is the actual output, $K_{t}$ is the capital stock, $L_{t}$ is the labor input, $\alpha, \beta$ are the average capital output share and labor output share respectively.

Assuming that the return on scale is constant, and making logarithmic transformation, the following regression model is constructed to calculate TFP and its growth rate.

$$
\begin{aligned}
& \ln \left(Y_{t} / L_{t}\right)=\ln (A)+\alpha \ln \left(K_{t} / L_{t}\right)+\varepsilon_{t}, \alpha+\beta=1 \\
& \text { TFP is, } \\
& \quad T F P_{t}=\frac{Y_{t}}{K_{t}^{\alpha} L_{t}^{\beta}}
\end{aligned}
$$

The growth rate of TFP, namely technological innovation is,

$$
G T F P_{t}=\frac{T F P_{t}}{T F P_{t-1}}-1
$$

\subsection{Long-term impact - Cointegration regression} model

First, it is determined that many variables are of the same order and single integer. Then, the long-term equilibrium equation, i.e. cointegration regression equation, is estimated by OLS method.

$$
\begin{gathered}
y_{t}=\beta_{0}+\beta_{1} x_{t}+u_{t} \\
\widehat{y_{t}}=\widehat{\beta_{0}}+\widehat{\beta_{1}} x_{t} \\
\text { Retain residual, } \\
\widehat{e_{t}}=y_{t}-\widehat{y_{t}}
\end{gathered}
$$

Lastly, test the stationarity of the residual term, if the residual term is a stationary sequence, there is a cointegration relationship between variables, that is, there is a long-term equilibrium relationship.

\subsection{Short-term dynamic effect - Impulse response model}

The impulse response function describes the response of the intrinsic variable to the shock with the error changing into a standard deviation. Therefore, we can use the 
impulse response function to study whether and how a standard deviation impact on employment in a short period of time. It is based on the VAR model. Before establishing VAR model, we uses Granger causality test to judge whether there is causality between scientific and technological innovation and employment.

\section{Empirical analysis}

The model of TFP is regressed by OLS, and the result shows that $\alpha=0.918$, then $\beta=0.082$. The final calculation results are as follows,

$$
\begin{gathered}
\ln \left(Y_{t} / L_{t}\right)=-0.6128+0.9180 \ln \left(K_{t} / L_{t}\right) \\
(0.0420)(0.0372) \\
(-14.5944)(24.7142)
\end{gathered}
$$$$
R^{2}=0.9429 \quad F=610.7890 \quad n=39 \quad D W=0.0586
$$

Table1. Descriptive statistics of cointegration regression model

\begin{tabular}{|c|c|c|c|c|}
\hline Variable & Coefficient & Std. Error & t-Statistic & Prob. \\
\hline C & -13003.12 & 5385.5870 & -2.4144 & 0.0210 \\
\hline LNTFP & 20381.44 & 2412.3010 & 8.4490 & 0.0000 \\
\hline LNGDP & 9144.76 & 474.7578 & 19.2620 & 0.0000 \\
\hline R-squared & 0.9447 & & F-statistic & 307.7044 \\
\hline $\begin{array}{c}\text { Adjusted R- } \\
\text { squared }\end{array}$ & 0.9417 & & $\begin{array}{c}\text { S.E. of } \\
\text { regression }\end{array}$ & 3021.1270 \\
\hline
\end{tabular}

Long term equilibrium,

$$
\widehat{p_{t}}=-13003.12+20381.44 \ln T F P_{t}+9144.76 \ln G D P_{t}
$$

When the GDP level is kept unchanged, the partial effect of scientific and technological innovation is 20381.44, which means that every $1 \%$ increase of scientific and technological innovation will promote the increase of employment by $203.8144 \%$.

\subsection{Short-term dynamic relationship}

This paper uses impulse response model to reflect the short-term dynamic relationship between technological innovation and employment. It describes the impact of an endogenous variable in VAR model on other endogenous variables. Figure 1 shows the dynamic demonstration of employment (GL) after being impacted by technology innovation (GTFP). The figure shows that scientific and technological innovation has a negative impact on employment, which gradually turns into a positive impact after holding two periods, and reaches the maximum in the third period. After that, the positive effect gradually weakened, and by the sixth period, it had become stable and weak.

\subsection{Long-term equilibrium relationship}

We take total factor productivity as an alternative variable of scientific and technological innovation, and introduce the control variable GDP. In order to explain the significance of the model coefficient easily, we take logarithm and make linear logarithm model regression.

The test of the stationarity of the variables shows that all the variables are integrated of order one I (1), so the cointegration regression model can be established to study the long-term equilibrium relationship.

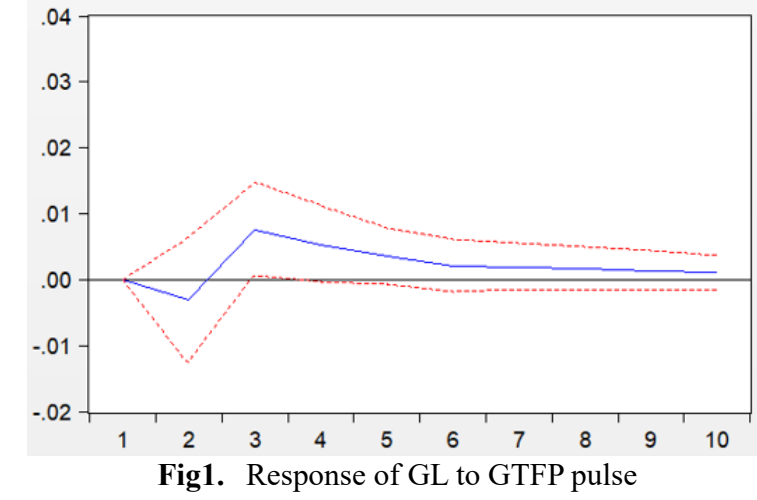

\section{Conclusions}

Technological innovation has double-sided effect on the total employment. There has been a relatively stable promotion effect for a long time. In the short-term impulse response function, after the impact of a standard deviation new interest rate of technological innovation, the total employment first shows a negative change, and then shows a more stable positive change. That is to say, in the first two years of technological shock, the destruction effect is relatively strong in general, and the destruction effect is the strongest in about 1.5 years. The creation effect gradually exceeds the destruction effect after 2 years, occupying a dominant position and manifested as the creation effect on employment. And this effect plays the largest role in the next six months, then gradually declines, but still manifested as the creation effect. After a long-term stable period of time, the impact of earlier shocks gradually disappeared. 
At present, the employment structure in China does not match the demand structure of the market, the vacancy and unemployment coexist. In addition, China's technological innovation ability is limited, the development momentum of emerging industries is insufficient, and its employment potential cannot be fully exploited, which results in the strong employment crowding out effect of China's technological innovation and significant employment problems. Therefore, we should vigorously develop education and technological innovation, improve the quality level of labor force, and create enough matching labor force for the adjustment of industrial structure driven by scientific and technological innovation.

\section{Acknowledgment}

I'm particularly grateful to my tutor for his instruction, my classmates for her accompany, and my family 's support forever.

\section{References}

1. Xianping Bi, Jianyi Zhao, The impact of technological innovation on China's total employment and structure. Statistics and decision making, 2007, pp.71-72.

2. Guangdong Wang, Rensun Ye and Lei Wang, The impact of technological innovation on Employment: regional differences and policy choices, China soft science, 2008, pp.151-160.

3. Zhen Chen, Employment effect of scientific and technological innovation and its formation mechanism. Journal of Southwest University for Nationalites (Humanities and social sciences edition), 2011, No.32, Vol.10, pp. 93-97.

4. Maosheng Ran, Yali Zou, Empirical Study on employment effect of technological innovation based on VAR model, Industrial technology economy, 2014,No.33, Vol.7, pp.110-116.

5. Youping Cui, Yuguo Jin and Xiao Wang, Empirical analysis of the impact of technological innovation on employment in China: 1995-2013, Comparison of economic and social systems, 2015,Vol.4, pp.154-164.

6. D. Ricardo, On the Principles of Political Economy and Taxation. Commercial Press, 1817.

7. J. A. Schumpeter, History of economic analysis, Beijing Commercial Press, 1980.

8. P. M. Romer, Increasing Returns and Long-Run Growth, Journal of Political Economy, 1994. 